\title{
Prevalence of Hemoglobin S in Blood Donors in the Hospital Dr. Agostinho Neto, Praia City - Cape Verde
}

\author{
Leonel Barbosa Gonçalves, Elves Heleno Gomes Duarte, Marilena Djata Cabral \\ Department of Science and technology, University of Cape Verde, Praia City, Cape Verde
}

Email address:

leonelb87@gmail.com (L. B. Gonçalves), ehelegam@hotmail.com (E. H. G. Duarte), marilenadcabral@gmail.com (M. D. Cabral)

\section{To cite this article:}

Leonel Barbosa Gonçalves, Elves Heleno Gomes Duarte, Marilena Djata Cabral. Prevalence of Hemoglobin S in Blood Donors in the Hospital Dr. Agostinho Neto, Praia City - Cape Verde. Science Journal of Public Health. Vol. 3, No. 5, 2015, pp. 600-604.

doi: $10.11648 /$ j.sjph.20150305.11

\begin{abstract}
Hemoglobin S is a hereditary blood pathology, with higher prevalence worldwide. The homozygous patients have anemia in varying degrees of severity, while heterozygous carrier sickle cell trait may have hematocrit and hemoglobin which can be used in donation. The hemoglobin carrier erythrocyte characteristics does not allow you to be a good donor blood transfusion undesirable effects may be due to both the potential sickling as to changes in hemotherapeutic product as a result of processing and storage. In Cape Verde, no studies related to the prevalence of hemoglobin S and program for screening of hemoglobin $\mathrm{S}$ in the blood donors are reported. The main objective of this study was to determine the prevalence of hemoglobin S in blood donors attended in the Dr. Agostinho Neto Hospital, between August to October (2013). Sickling of red blood cell technique was performed. Between samples we found that four donors from $104(3.9 \%)$ that were screened had positive results, gender, age and hemoglobin concentration, naturally, county of residence, blood groups and regular donors were associated with the presence of such a hemoglobin variant. The results underscore the importance of screening this abnormality in the blood donors and further studies must be performed. Also we recommend the implementation of information strategies, awareness, early detection and treatment of diseases associated with hemoglobin S.
\end{abstract}

Keywords: Cape Verde, Blood Donation, Hemoglobin S, Prevalence

\section{Introduction}

Hemoglobin is a protein in red blood cells which mainly transports oxygen and $\mathrm{CO} 2$. It consists of two parts: a protein, comprises four globin chains which are grouped forming a tetramer and contains a heme group iron molecule ${ }^{9}$.

Hemoglobin $\mathrm{S}(\mathrm{HbS})$ variant hemoglobin, results from the point mutation at position 6 of the $\beta$ globin chain gene (substitution of glutamic acid for valine), with consequently changes the physicochemical properties of molecule $e^{1,4}$.

Genetic hemoglobin change is a group of high clinical relevance and has been important in public health. Thousands hemoglobin variants have been described. However, the vast majority are not clinical important ${ }^{12}$.

Individuals with sickle cell trait (HbAS) are considered healthy carriers and such genotype are called sickle cell trait. Therefore, they are clinically and hematogenously healthy and able to donate blood. ${ }^{1,4}$

According Lisot in 2003, the carriers of sickle cell trait, Hemoglobin SC and other related hemoglobinopathies may present values of hematocrit and hemoglobin that may be possible to donate blood ${ }^{6}$. However, in this situation the actual morbidity is quite controversial, since there are reports of clinical complications after received blood and exposed to low oxygen tension environment ${ }^{1}$.

Hemoglobin $\mathrm{S}$ cases just happened when clinician's observed the publication splenic infarcts in AS pilots staying in unpressurized cockpit after aircraft flights. However, in normal conditions, the carriers of sickle cell trait showed no clinical signs ${ }^{1}$.

While the heterozygote individuals present do not usually evident clinical manifestations are reports of clinical complications, and even sudden death in patients exposed to conditions of low oxygen tension such as general anesthesia, diving, pressurized aircraft in flight also dehydration in strenuous physical exertion, severe respiratory infections, heart failure and respiratory acidosis episodes, which can lead to sickling of erythrocytes, causing vascular complications, splenic infarction and renal complications and genitourinary tract ${ }^{1}$.

The erythrocyte characteristics of sickle cell trait carrier 
not allow to be a desirable blood donor ${ }^{4}$. The undesirable effects of transfusion, when it comes to erythrocytes containing $\mathrm{HbS}$ may be due to the sickling potential in the receiver as well as the changes in hemotherapeutic product caused by processing and storage ${ }^{7,1}$.

Heterozygous red blood cells should not be used in patients with sickle cell anemia during sickling crisis, newborns (especially premature), and individuals in severe hypoxia $^{1,4,11,13}$.

In Cape Verde, the material used during blood donation and the procedures is regulated by Law No. 18 / VII / 2007 of 26 November, traces of infectious agents and pre-transfusion tests. However, none rules have been documented related to established the mandatory screening of $\mathrm{HbS}$. After revising the literature and found lacking studies related to sickle cell disease in the blood donation, we decide to carry out this study.

Therefore, the objective of this study was to determine the prevalence of $\mathrm{HbS}$ and its relationship to the characteristics of the study population.

\section{Methodology}

\subsection{Study Population}

This was a prospective study, applying quantitative and qualitative approaches that determined the prevalence of hemoglobin $\mathrm{S}$ in the blood donors attended in Dr. Agostinho Neto Hospital during the period from August to October 2013. We discuss the nationality, age, blood group, donation frequency, county and hemoglobin concentration. All data was obtained from blood bank. All data was well organized in computer.

The project of this study was previously approved by the National Committee for Ethics in Research for Health (CNEPS). We followed all measures established in Decree Law No. 26/2007 of 30 July which includes the free signature and informed consent by the patients. Also we guaranteed not harm the physical integrity of patients.

\subsection{Sickling Cell Test}

The detection of hemoglobin $\mathrm{S}$ was performed mixing $10 \mu \mathrm{L}$ of whole blood with of $50 \mu \mathrm{L}$ sodium metabisulphite $\left(\mathrm{Na}_{2} \mathrm{~S}_{2} \mathrm{O}_{5}\right)$ 2\%. In this technique the deoxy-Hb form polymers, causing change in the morphology of the red blood cells, acquiring the sickle shape. ${ }^{1}$

\subsection{Statistical Analysis}

All collected data were organized in a database created using Microsoft Excel 2010 and imported to the computer statistical program R (R Core Team, 2013). To characterize the profile of participants' frequency comparison tests were used and average for two and / or more groups according to the nature of the variables was determined.

To determine the factors related to the presence of hemoglobin S, logistic regression was calculated. To assess the degree of association, the strength of association ("odds ratio") was determined using the exponential value estimated by the model. All statistical analyzes were conducted at a confidence level of $95 \%(\alpha=0.05)$.

\section{Results}

According to the results we found significant differences between sex of donors $(\chi 2=19: 47 ; \mathrm{p}<0.001)$, with a predominance of males $(72.12 \%)$. Regarding the age of the donors, we observed the variation between 18 and 58 years. However there were no significant differences in their average when sex and age was compared $(\mathrm{W}=1225$; $\mathrm{p}$-value $=0.32$ ).

The numbers of blood donors varied significantly by residence. More than $75 \%$ of donors was from Praia. Only one participant had permanent residence outside of the Santiago Island. Blood group $\mathrm{O}+$ was the most prevalent (44.2\%). A important number of donors participants has blood group A + (22.1\%), + B (12.5\%) and O- (12.5\%).

During the period of study we found 104 donors, which represent $3,9 \%$ with positive result for the presence of hemoglobin S.

The logistic regression analyses showed the association between the variables and the presence of $\mathrm{HbS}$, compared to females, males were significantly more associated with the presence of $\mathrm{HbS}(\mathrm{OR}=1.04)$ fig. 1 .

The variation of age $(\mathrm{OR}=0.97)$ and hemoglobin concentration $(\mathrm{OR}=0.36)$ fig. 2 , was linked to the presence of $\mathrm{HbS}$. Santiago Island, São Nicolau and Poland were the most associated with the presence of $\mathrm{HbS}(\mathrm{OR}>10)$ fig. 3 .

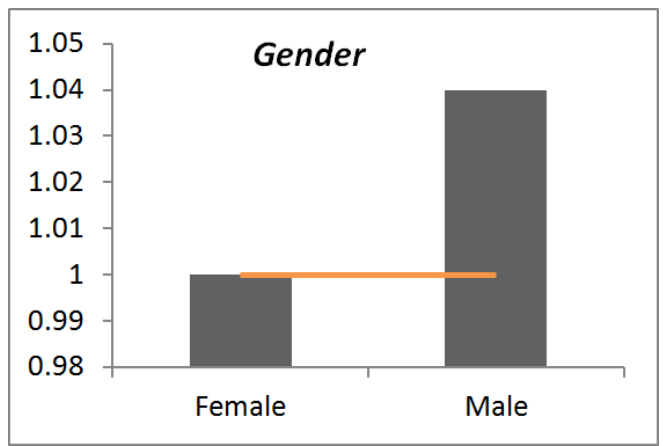

Fig. 1. Logistic regression relating Gender of blood donors and presence of hemoglobin $S$.

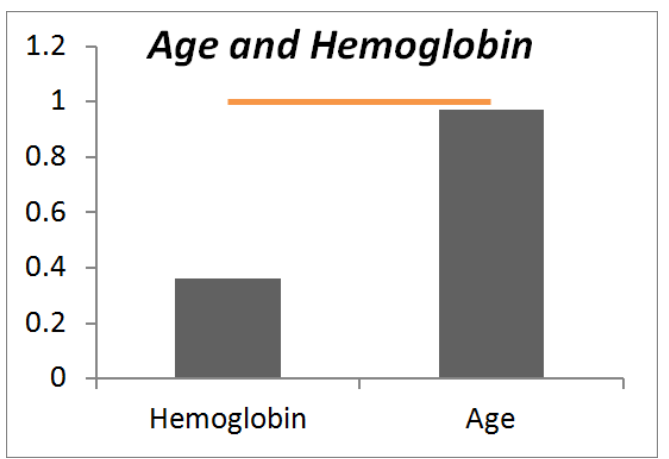

Fig. 2. Logistic regression relating Age and hemoglobin of blood donors and presence of hemoglobin $S$. 


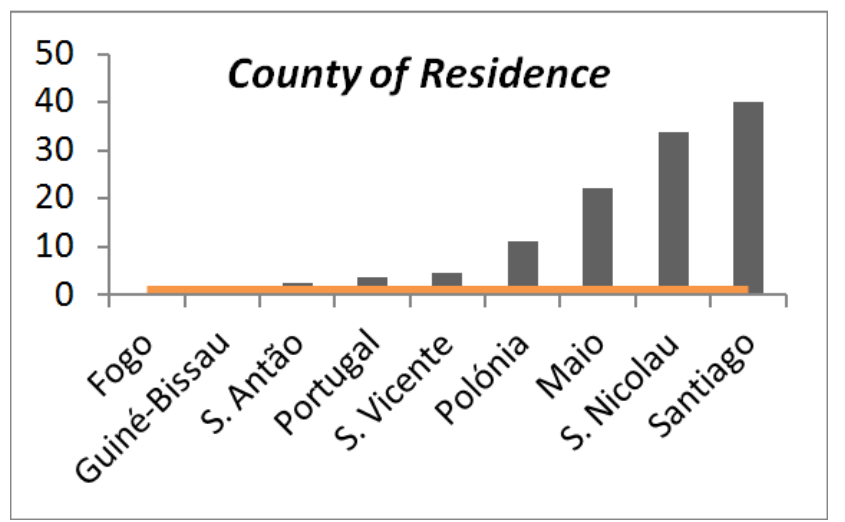

Fig. 3. Logistic regression County of Residence and presence of hemoglobin $S$.

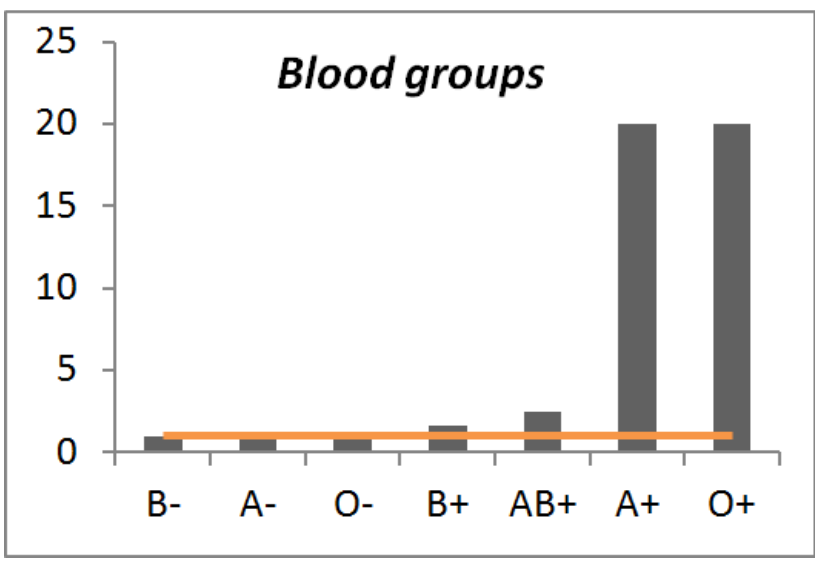

Fig. 4. Logistic regression blood groups of blood donors and presence of hemoglobin $S$.

When comparing blood groups, we verified that the groups $\mathrm{O}+$ and $\mathrm{A}+$ were among the most associated (OR $>10)$ fig.4. Surprisingly we found some regular donors (2nd time or more per year) were significantly associated with the presence of $\mathrm{HbS}$ than those who donated blood for the first time, fig.5.

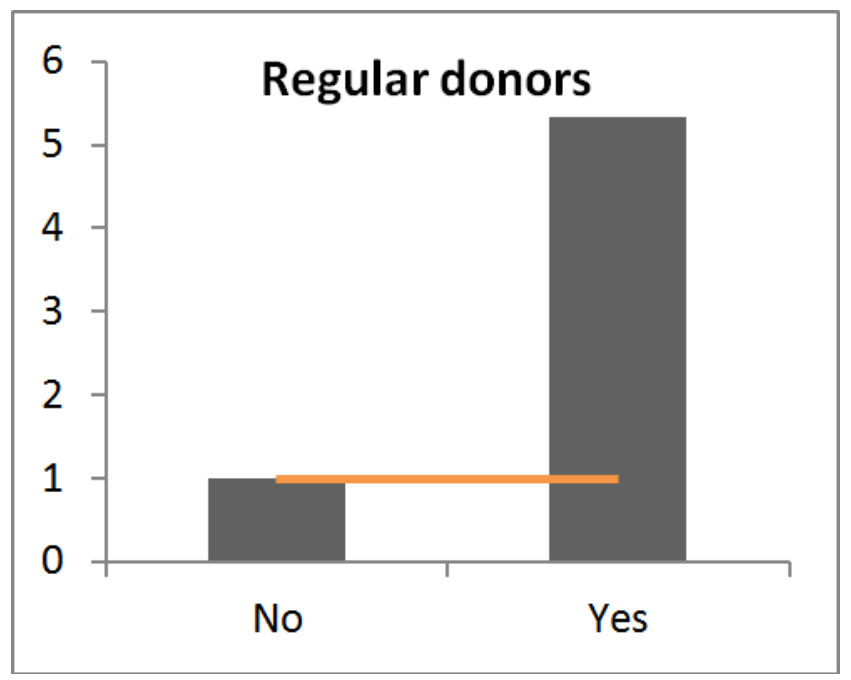

Fig. 5. Logistic regression regular donors and presence of hemoglobin $S$.

\section{Discussion}

The present study was performed on 104 of non remunerated voluntary blood donors attended in Blood Bank of Dr. Agostinho Neto Hospital. We found a predominance of males blood donors $(72.12 \%)$ similar results were found in other studies $1,4,13,14$

The relatively lower numbers of female donors could be related to the physical state such as anemia and by Law No. 18 / VII / 2007 to 26 November, which established that women should donate every 4 months and man every 3 months. The majority of blood donors in this study ranged from 18-58 years. Most donors were from Praia City. This may be due to localization of blood bank in this city.

The prevalence of $\mathrm{HbS}$ in this study was $3.9 \%(\mathrm{n}=4)$, the Prevalence of $\mathrm{HbS}$ found in this study is low compared to other developed studies in Cape Verde, this may be due to only three months study peroxide (104 donors), shortening the decision of the study period just three months it should be a number of reasons. First, dealing with a first cross-sectional study, the aim is certainly to have a view of the object of study of the situation in the place of study (Blood Bank of the Hospitals of Cape Verde Central). Secondly, as you know, the Cape Verdean legislation establishes that men should give blood in a three months interval while women every four months. Thus, in order to minimize the possibility of including the same individual twice (which would result in duplication of a negative or positive result and skewing the particular prevalence), reduced the period of study in order to ensure that there would be no time one individuals return to the Blood Bank with the intention of donating blood.

Another's studies showed a higher prevalence of $\mathrm{Hb}$, specifically in individuals from tropical Africa and among blacks' countries where the slave trade occured. The hemoglobin $\mathrm{S}$ gene is also found in another's populations. However this prevalence is lower when compared with African countries and Brazil.

The prevalence identified in the study is in line with the region surrounding the Mediterranean Sea, including the northern coast of Africa, Turkey, Lebanon, Syria and Greece and in Portugal. In these regions the prevalence is between 2 and $5 \%$. However, it is important to note that within those regions (or countries) various prevalence considerably among racial groups, as in the case of Eti-Turks in Turkey (14\%) and between Khazramah Syria $(25 \%)^{9}$.

According Naoum (2000), in Brazil, in the northeast, the prevalence of hemoglobin $\mathrm{S}$ is $4.05 \%{ }^{13}$. According to Aguiar \& Maia (2011), the regional Blood Center of Montes Claros, Minas Gerais, the prevalence of hemoglobin S is $4 \%{ }^{1}$

More studies should be performed on blood donors with more sensitive methods and a longer study period to determine the real prevalence of $\mathrm{HbS}$ in blood banks in Cape Verde.

The hemoglobinopathies is an important public health problem. Study by Cruz et al ( 1979), showed a genotype frequency: $\mathrm{HbAS}=7.86 \%, \mathrm{HbSS}=0.16 \%$ and $\mathrm{HbAA}=91.36 \%$ 3 , higher than those observed in our study. Also another study 
carried out by Alves (2010), reported a prevalence of $\mathrm{HbAA}=92 \%, \mathrm{HbAS}=7 \%$ and $\mathrm{HbSS}=1 \% \quad(\mathrm{n}=217)$. These results are probably due to the difference in sample size and the methodology applied. Since the methodology followed is more sensitive than sickling technique used in this study ${ }^{5}$.

Logistic regression showed a greater association of presence of $\mathrm{HbS}$ with sex $(\mathrm{OR}=1.04)$. This may be explained by the higher number of male donors attended. However, gender is not a crucial factor related to the presence of $\mathrm{HbS}$, since genes that express the synthesis of the $\beta$ globin chain are not restricted by this condition ${ }^{1,4}$. Also the age not influences the gene expression.

According, Murao \& Ferraz (2007) the concentration of $\mathrm{Hb}$ in $\mathrm{HbAS}$ carriers may be below $30 \%$, with hemoglobin concentration ranging from 13 to $15 \mathrm{~g} / \mathrm{dl}$, which correlated with the results found in male donors, where the values of $\mathrm{Hb}$ are within the standard for donation ${ }^{8}$.

Depending on the residence, we conclude that all carriers of $\mathrm{HbS}$ were from Santiago Island. According to data, in this island, resides a greater number of males compare to female. The model is identified as a risk factor for the presence of $\mathrm{HbS}$.

The high association between $\mathrm{HbS}$ and Poland $(\mathrm{OR}=10)$ and São Nicolau Island $(\mathrm{OR}=33.8)$, may be due to the model risk factors for the presence of $\mathrm{HbS}$.

This is, to our knowledge, the first study on the prevalence of $\mathrm{HbS}$ in Blood Bank to take place in the archipelago of Cape Verde, as emphasized in the work. Therefore, we considered this study (hemoglobin S) important for public health and should be revised in national legislation. Also, this study provides data and fundamental information which may be the base for health care plans, especially those related to blood transfusion.

WHO Working Group recommends the population survey of the prevalence of hemoglobinopathies and thalassemia, because it allows the identification of heterozygous and homozygous Moreover, these programs also have a responsibility to clarify and educate patients ${ }^{17}$. Therefore, the identification of people with sickle cell trait or heterozygous for hemoglobin $\mathrm{S}$ is very relevant. These people should have the knowledge of their genetic condition, knowing that present a high risk of bearing children with sickle cell anemia and heterozygous children, who are parents of other future sickle patients ${ }^{16}$.

The importance of screening $\mathrm{HbS}$ may increase the interest for the preventive detection of this variant, the possibility the ability to obtain offspring carrying the same trait or sickle cell anemia. This also will allow early detection of this abnormality in children and hence proper medical attention. If the $\mathrm{HbS}$ is detected prior to transfusion, the health professional may carry about the quality of transfused blood which prevents many complications, cost and risk for the patient.

In addition to the donor screening, these results further highlight the importance for screening in the population to identify carriers of this variant hemoglobin. Also this approach may be important to inform the possible genotype of descended avoiding complications and further costs.

\section{Final Consideration}

In this study, we concluded that the prevalence of hemoglobin $\mathrm{S}$ is $3.9 \%$ in blood donors attended in the blood bank. These results also underline the need to carry out further studies in other populations.

This result will outline guidelines on this issue which may be the base for the implementation of strategies, awareness, early detection and treatment of this disease.

Such studies provide precious information for the inclusion policy decision of mandatory screening of hemoglobin variants before blood donation and transfusion. Thus contributing significantly to the improve the health care system in Cape Verde.

Early detection of carriers of the Hemoglobin $\mathrm{S}$ or hemoglobinopathies and allows counseling and/or genetic counseling and treatment to patients. National Health System Cape Verdean should focus on implementation of the National Comprehensive Care System for People with sickle cell disease hence it can function as a means to prevent costs for the health system if there is an increase in the number of carriers.

\section{Acknowledgement}

The author thanks Dr. Carlos Neves and Blood Bank team of the Dr. Agostinho Neto Hospital for their support and cooperation in carrying out this work.

\section{References}

[1] Aguiar, K. M., Maia, C.N. (2011). Prevalence of hemoglobin $\mathrm{S}$ in blood donors at the Hemocentro Regional in the Town of Montes Claros, Minas Gerais. RBAC. 43(4): 284-287.

[2] Alves, J. B. (2010). Malaria epidemiology in Cape Verde Human Genetic factors and population structure of the mosquito vector. Institute of Hygiene and Tropical Medicine, Master's thesis, University Nova de Lisboa: 205p.

[3] Cruz, J. M., Brandão, C., Barreira, M.J., Amorim, A \& Rebimbas, M.C. (1979). Genetic Studies in Cape Verde Archipelago (hemoglobin, haptoglobin and $\mathrm{ABO}$ and $\mathrm{MN}$ blood groups). 36: 9p.

[4] Grignani C, A. C., Iamamoto C, Gonçalves T, Mashima D et al. (2006). Prevalence of hemoglobin AS among blood donors from Londrina - Paraná.RBAC. 38(4): (259-62).

[5] Hicks, E. J., Griep, J. A., Nordschow, C., D. (1973). Comparison of Results for Three Methods of Hemoglobin S Identification. Clin. Chem. 19/5: p. 533-535.

[6] Lisot, C. L. A. (2003). Screening of hemoglobinopathies in blood donors in Italian colonization area of Rio Grande do Sul, Brasil.School medicine Dissertation. University Federal do Rio Grande do Sul.: 144p.

[7] Marques, J. R. (1994). Transfusion of red blood cells containing hemoglobin S.BolSoc Bras HematolHemoter. XVI (166): 229-232. 
[8] Murao, M., Ferraz, M.H.C. (2007). Sickle cell trait heterozygosity for hemoglobin S. Rev. bras. hematol. hemoter. 29(3): 223-225.

[9] Naoum, P. C., Naoum, F.A. (2004). Sickle cell disease. S. P. Sarvier.

[10] Oshiro, M., Neto, A.P., MighitaM, K., Watanabe, C.I., Palharin,i D.L.B. (1999). Comparative study of solubility tests, sickling and gel-centrifugation for population detection of hemoglobin S. Journal.InstAdolfo Lutz. 58: 53-56.

[11] Paiva, E., Silva, R.B., Ramalho, A.S. (1997). Risks and benefits of genetic screening: the sickle cell trait as a model in a Brazilian population. Book. Health Public. 13(2): 285-294.

[12] Rodrigues, A. S. N., Nascimento, R.E., Castelo, N.M. (2012). Sickle cell trait: the impact on public health. Equatorial Science. v, 2 - No 2.ISSN 2179-9563: 6p.
[13] Naoum, P. Prevalence and control of hemoglobin S. Rev. Bras. Hematol. Hemoter., 22 (2):142-148.

[14] Varela, E. M. M. (2011). Predisposing factors for membership to blood donation among students at the University of Cape Verde - Campus Palmarejo. Department of Science and Technology. Thesis, University of Cape Verde: 68p.

[15] Freire, A. J. C. (2012). Serologic profile of blood donors from Santiago North Health Region from 2008 to 2011. Department of Science and Technology. Thesis, University of Cape Verde: $80 \mathrm{p}$.

[16] Rodrigues, ASN, Nascimento, RE, Castle, NM (2012). Sickle cell trait: the impact on public health. Equatorial science. v,2 Number 2.ISSN 2179-9563: 6p.

[17] WHO Working Group. (1982). Hereditary anemia. genetics basic, clinical features, diagnosis and treatment. WHO, 60: 643-60. 